\title{
Development of Visualization System for Valve Sealing Evaluation
}

\author{
Chaowen Zhu' ${ }^{\text {, Lanzhu Zhang }}{ }^{\mathrm{b}}$ \\ School of Mechanical and Power Engineering, East China University of Science and Technology, \\ Shanghai 200237, China \\ am15800630837@163.com, ${ }^{b}$ lzzhang@ecust.edu.cn
}

Keywords: Floating ball valve, APDL, sealing evaluation, leakage rate.

Abstract: Valves are widely used in process industry as control devices and their sealing property is very important to the routine work of fluid-equipment. In order to improve sealing property of valves, taking the case of floating ball valve, visualization system for valve sealing evaluation was developed based on VB. ANSYS secondary developed by APDL in this system was acted as a background program to analyze the sealing contact of floating ball valve. By extracting calculated results, the system can accomplish the analysis and evaluation of sealing property and predict the leakage rate of valves. It was demonstrated that this system could satisfy the requirement of sealing property analysis and provide guides for the design and production of valves.

\section{Introduction}

In recent years, with the development of petroleum, natural gas and chemical industry, the market demand for valves is continuously increasing and requirements of valves' quality have risen higher and higher. At the same time, in order to improve social environmental, the limit for leakage of process industry have been more and more stringent. Valve leakage is the main source of passive leakage in process industry, accounting for $66.7 \%$ of the total passive leakage of equipment. Traditional method of valve design is mainly based on analogy and experience [1]. This method lacks evaluation of valve sealing property and prediction of valve leakage rate, which causes that lots of experiments are needed to be carried out to verify the valves' quality and the cost of valve design increases. Therefore, the development of valve sealing evaluation system is particularly important.

Visualization system for valve sealing evaluation took floating ball valve as an example here. ANSYS is secondary developed based on Visual Basic and APDL. The sealing surface of floating ball valve is simulated by finite element method and sealing pressure is extracted. The flowchart of this system is shown in Fig.1. First of all, relevant parameters are input, including sizes of valve parts, material performance parameters and so on. Then, the sealing property of valves is simulated and evaluated. What's more, optimal design for valve seat and prediction of leakage rate can be carried out if the valve has poor sealing property. 


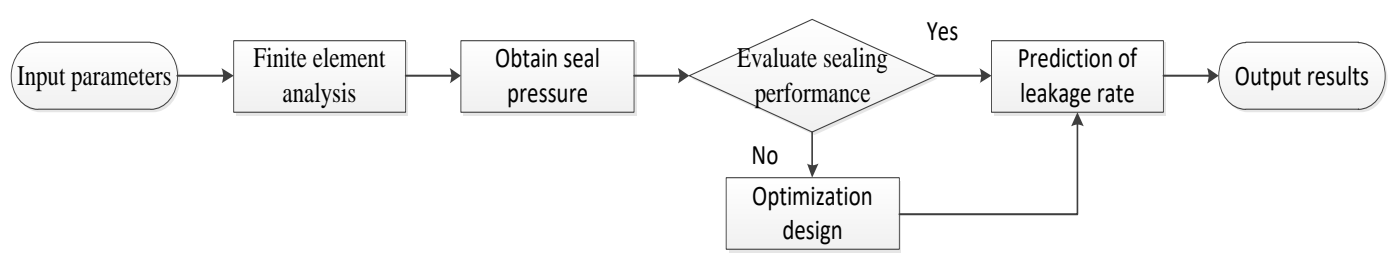

Fig. 1 Flowchart of visualization system for valve sealing evaluation

\section{Analysis of Sealing Property in a Floating Ball Valve}

\subsection{Sealing Principle}

The structure of a floating ball valve is shown in Fig.2. The inlet valve seat is on the left of valve core and the outlet valve seat is on the right. Medium flows from left to right just as shown in this figure. When the floating ball valve is closed, the left surface of valve core is under the medium pressure $(P)$ and the pre-tight pressure of inlet valve seat $(F)$, which results in the tight contact between valve core and outlet valve seat [2]. The inlet valve seat cannot be tightly contacted with valve core due to the medium penetration, so it isn't acted as a sealing component. In contrast, the outlet valve seat is under the pressure $(N)$ from valve core which leads elastic deformation of outlet valve seat. Therefore, a sealing surface with enough sealing pressure which can prevent the flow of medium is formed between valve core and outlet valve seat. When the medium pressure is stronger, the sealing pressure will also increase.

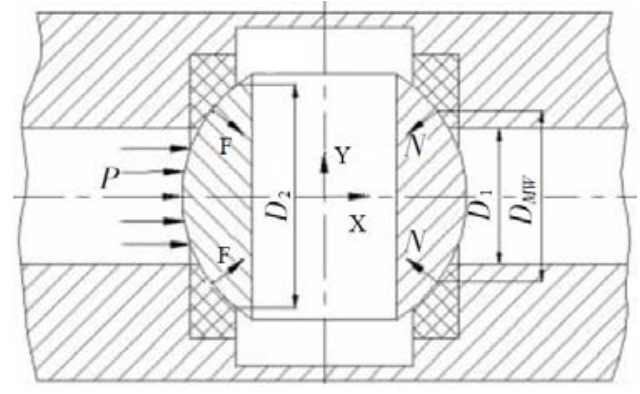

Fig. 2 Structure of floating ball valve

To ensure that there is no medium leaking when valve is closed, sealing pressure $(q)$ between valve core and outlet valve must be greater than required pressure $\left(q_{b}\right)$ and less than allowable pressure $([q])$.

$$
q_{b} \leq q \leq[q]
$$

If sealing pressure is less than required pressure, the contact between valve core and outlet valve seat is insufficient and the medium will leak. If sealing pressure is greater than allowable pressure, plastic deformation will be formed in the outlet seat and also leads to the leakage of medium.

\subsection{Finite Element Simulation}

According to the above principle, only valve core and outlet valve seat should be considered when finite element analysis model of sealing property is established. In order to simplify calculation, the groove on the top of valve core which is used to connect valve core and stem is removed and the through-hole in the middle of valve core is retained. In the aspect of meshing, the element types of SOLID185 is used to mesh valve core automatically and the element types of VISCO107 is used to mesh valve seat by sweeping [3]. Gird size can be selected in the system. The smaller grid is, the more 
accurate calculation is but calculation is larger and consuming time is longer. Valve seat is generally soft material, so the surface of valve seat is acted as contact surface in contact analysis meshing by the element types of CONTA174, while valve core acted as target surface is meshed by the element types of TARGE170.

In terms of constraints, the displacement of right surface of valve seat is limited in direction of $\mathrm{X}$ but unlimited in direction of $\mathrm{Y}$ and $\mathrm{Z}$. The displacement of outside cylinder surface of valve seat is limited in direction of $\mathrm{Y}$ and $\mathrm{Z}$ but unlimited in direction of $\mathrm{X}$, to ensuring that there is no interference between valve seat and valve body. In terms of loads, valve core is subjected to pressure from medium and inlet valve seat. Medium pressure $\left(Q_{1}\right)$ and pre-tight pressure $\left(Q_{2}\right)$ calculation equations are shown in Eq.2 and Eq.3.

$$
\begin{gathered}
Q_{1}=\frac{\pi}{16}\left(D_{1}+D_{2}\right)^{2} P \\
Q_{2}=\frac{4 \delta_{1} E F_{m}}{\left(D_{1}+D_{2}\right)(\operatorname{tg} \theta-2 f)}
\end{gathered}
$$

In these equations, $D_{1}$ is the inside diameter of valve seat contact surface and $D_{2}$ is the outside diameter. Considering medium permeability, medium pressure ranges from the contact surface between valve core and medium to half of the contact surface between valve core and inlet valve seat.

After finishing all preprocessing work, this system will analyze the sealing contact of floating ball valve by running "Solve" command and obtain the contact stress distribution.

\subsection{Connection between System and ANSYS}

There are four tools for secondary development of ANSYS, including APDL, UPFs, UIDL and Tcl/Tk [4]. The connection between VB and ANSYS in this system is established by APDL command text file, which is easy to realize and does not need to add object type libraries in Visual Basic development environment. Firstly, the system creates corresponding APDL commands file according to relevant parameters of floating ball valve. Then, ANSYS Batch reads this file and began finite element calculation automatically in the result that result files including contact stress cloud chart and stress of each node in contact surface are created. When these result files are detected by the system, they will be read and shown in system interface. The flowchart is shown in Fig.3.

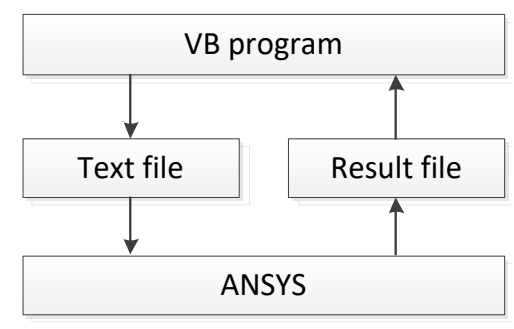

Fig. 3 Connection between VB and ANSYS

The system runs ANSYS in the background through "Shell" function. Different versions of ANSYS have some differences in "shell" function. The code is as follows:

Shell (ANSYS-path \& “-b -p ane3fl -i” \& APDL-drive \& -o output.txt, 1)

"ANSYS-path" is the directory of ANSYS program. "-b" represents batch work mode. Feature code of ANSYS is input after “-p”. The directory of APDL file is input after “-i”. 
After analysis and calculation of sealing property of floating ball valve are completed, the system will show relevant calculation results, including a contact stress cloud chart and distribution curves, which are shown in Fig.4.

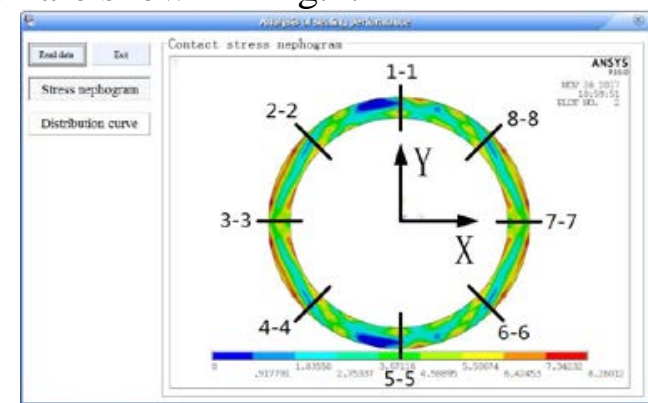

(a) Contact stress cloud chart

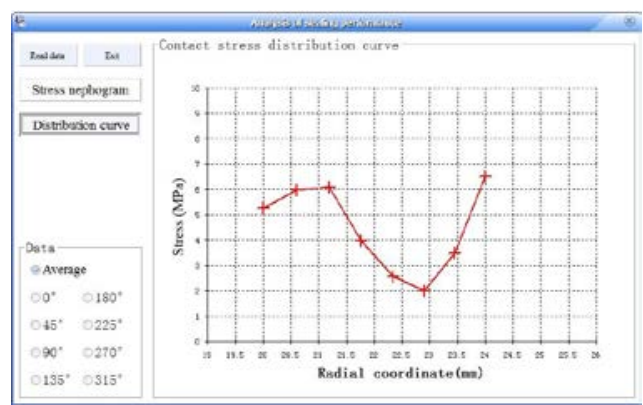

(b) Contact stress distribution curve

Fig. 4 Calculation results shown in system

\section{Evaluation of Sealing Property}

\subsection{Selection of Sealing Pressure}

In order to facilitate analysis, eight isometric sections are selected on the position of contact surface, as shown in Fig.4 (a). The difference of contact stress between inner and outer sides of each section is very large, so average sealing pressure of each section is calculated as evaluation index of this section. If the average sealing pressure of one section is larger than the required pressure, it means that no leakage occurs at that section. To verify that there is no leakage between valve core and outlet valve seat, it is necessary to calculate average sealing pressure of all sections and choose the minimum. If this minimum is greater than the required pressure, it means that the entire sealing surface does not leak and this valve has great sealing property.

Taking PN16 DN40 stainless steel floating ball valve of as an example, the average sealing pressures of eight sections from 1-1 to 8-8 are calculated when the medium pressure is 1.6 MPa. Results are shown in Table 1 . Sealing pressure is the lowest at the $5-5$ section because of the through-hole of valve core. The minimum average sealing pressure of 8 sections which is about 3.78 $\mathrm{MPa}$ is less than the required pressure which is $4.26 \mathrm{MPa}$ by calculating, so this valve is consider that has poor sealing property.

Table 1 Average sealing pressure of sections (MPa)

\begin{tabular}{ccccccccc}
\hline $\begin{array}{c}\text { Number of } \\
\text { section }\end{array}$ & $1-1$ & $2-2$ & $3-3$ & $4-4$ & $5-5$ & $6-6$ & $7-7$ & $8-8$ \\
\hline Pressure & 3.98 & 4.56 & 4.66 & 4.53 & 3.78 & 4.71 & 4.82 & 4.72 \\
\hline
\end{tabular}

\subsection{Optimal Design for Valve Seat}

Sizes of valve seat sealing surface include the inside and outside diameters of seat sealing surface. In general, the inside diameter is equal to the diameter of medium channel. Therefore, the optimal parameter is only the outer diameter in this system [5]. The method of optimal design is to reduce the outside diameter with a fixed step. Thus, the contact area between valve core and valve seat is reduced and the sealing pressure increases. The flowchart of valve seat optimal design is shown in Fig.5. 


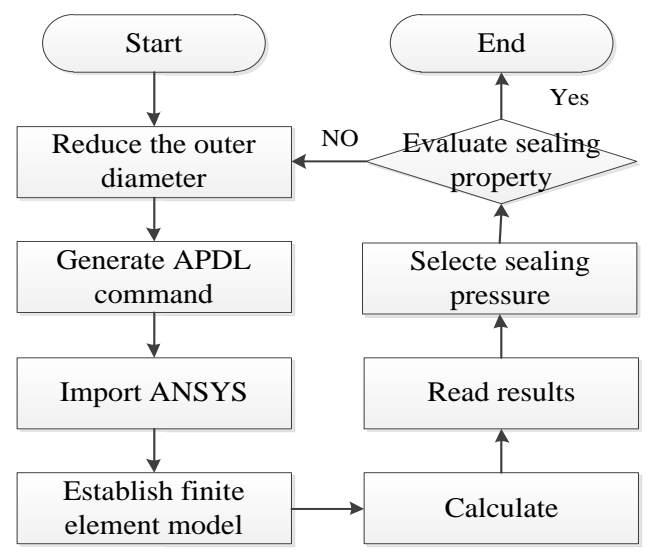

Fig. 5 Flowchart of optimal design for valve seat

After optimizing the valve seat size of the above valve, the size of outside diameter is adjusted from $48 \mathrm{~mm}$ to $46 \mathrm{~mm}$. The average sealing pressures of all sections after optimal design are shown in Table 2.

Table 2 Average sealing pressure of sections after optimal design (MPa)

\begin{tabular}{ccccccccc}
\hline $\begin{array}{c}\text { Number of } \\
\text { section }\end{array}$ & $1-1$ & $2-2$ & $3-3$ & $4-4$ & $5-5$ & $6-6$ & $7-7$ & $8-8$ \\
\hline Pressure & 6.80 & 5.23 & 6.06 & 5.22 & 6.78 & 5.28 & 6.12 & 5.24 \\
\hline
\end{tabular}

The minimum average sealing pressure of the eight sections (5.22 $\mathrm{MPa})$ is greater than the new required pressure (about $4.92 \mathrm{MPa}$ ) after optimal design, so this new valve meets the requirement of sealing property. The Contact stress distribution curves after and before optimal design are compared in Fig.6.

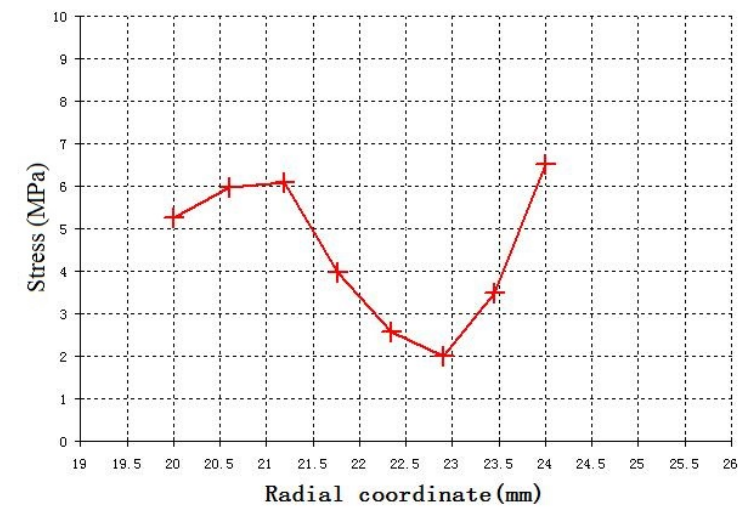

(a) Before optimal design

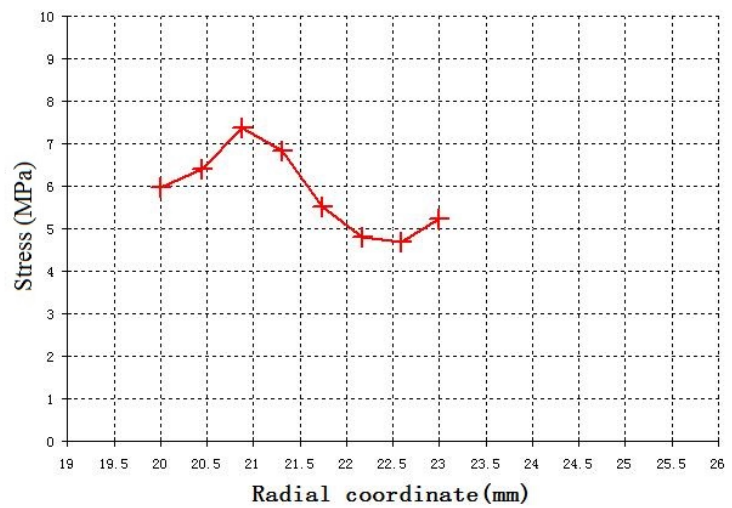

(b) After optimal design

Fig. 6 Contact stress distribution curves

\section{Prediction of Leakage Rate}

\subsection{Establishment of leakage model}

A leakage model is established and the leakage rate of a floating ball valve is calculated by Hertz contact theory and porous media theory in order to estimate the leakage rate of valve [6]. When the floating ball valve is closed, there is no relative motion between valve core and valve seat, so the type 
of sealing belongs to static sealing which relies on elastic deformation to obstruct medium flow. Due to the limitation of manufacturing technology, contact surface cannot be completely smooth so the leakage exists. The sealing surface between valve core and valve seat can be regarded as porous media modal with micro void.

Generally, the roughness of valve seat surface is greater than that of valve core surface. Therefore, it assumes that valve core contact surface is completely smooth and seat contact surface is rough. The rough peaks on valve seat surface can be represented by tightly arranged half hemispherical peaks. Due to the obvious difference in elastic modulus between valve core and valve seat materials, it is assumed that there is no deformation on valve core surface. According to Hertz formula, the compression height of half hemispherical peaks $(\delta)$ can be calculated.

$$
\delta=\frac{9 \pi^{2} q^{2}\left(1-\mu^{2}\right)^{2} r}{16 E^{2}}
$$

According to the compression height, the deformation volume of half hemispherical and the porosity of porous medium model $(\varphi)$ can be calculated.

$$
\varphi=1-\frac{\pi\left(2 r^{3}-3 r \delta^{2}+\delta^{3}\right)}{12 r^{2}(r-\delta)}
$$

The permeability $(K)$ can be calculated by Kozeny-Carman formula for homogeneous spherical granular porous media model.

$$
K=\frac{r^{2} \varphi^{3}}{45(1-\varphi)^{2}}
$$

The leakage rate of porous medium $(Q)$ can be calculated by Darcy formula.

$$
Q=K S \frac{\Delta p}{\eta L}
$$

The parameters' meanings in above equations are shown as follows.

$r$-the radius of half hemispherical peaks; $E$-The elastic modulus of valve seat; $q$-the sealing pressure; $\mu$-the Poisson ratio of valve seat; S-the area of sealing contact surface; $\Delta p$-the pressure of medium; $\eta$-the viscosity of medium; L-the width of sealing contact surface.

The leakage rate of floating ball valve will be estimated according to the above formulas in the leakage rate prediction interface of system.

\subsection{Experimental verification of leakage rate prediction}

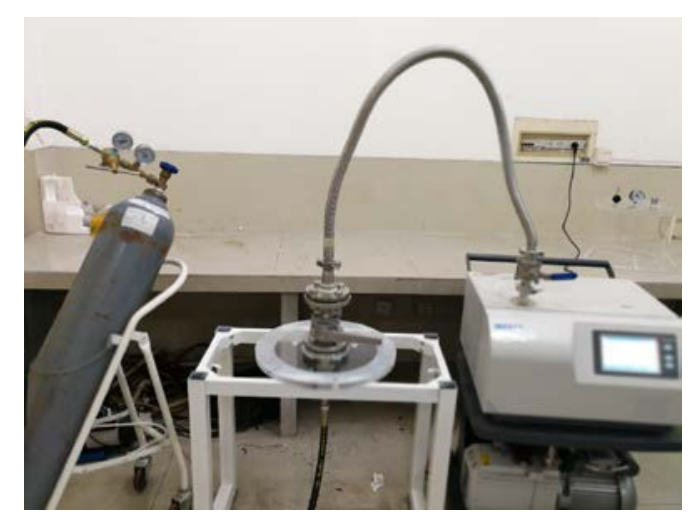

Fig. 7 Leakage detection device for floating ball valve 
In order to verify the accuracy of the above leakage rate prediction method, a leakage detection device for floating ball valve was built, as shown in Fig.7. Leakage rate of valve is accurately measured by helium mass spectrometer [7]. The helium tank is used to supply high pressure helium and the PN16 DN40 stainless steel floating ball valve is selected as experimental valve.

Injection method is used to detect leakage to ensure the accuracy of experimental results and simplify experimental procedures. The outlet side of floating ball valve as leakage chamber is highly evacuated and the inlet side is filled with helium.

After being calibrated by standard leak, helium mass spectrometer was run to detect leakage rates under different helium pressure. At the same time, another group of leakage rates were calculated by the system under the same conditions of structure and materials with experiments. The Contrast of experimental and predicted leakage rates is shown in Fig.8. According to this figure, the predicted and experimental leakage rates are in good agreement, which confirms the validity of visualization System for Valve sealing evaluation.

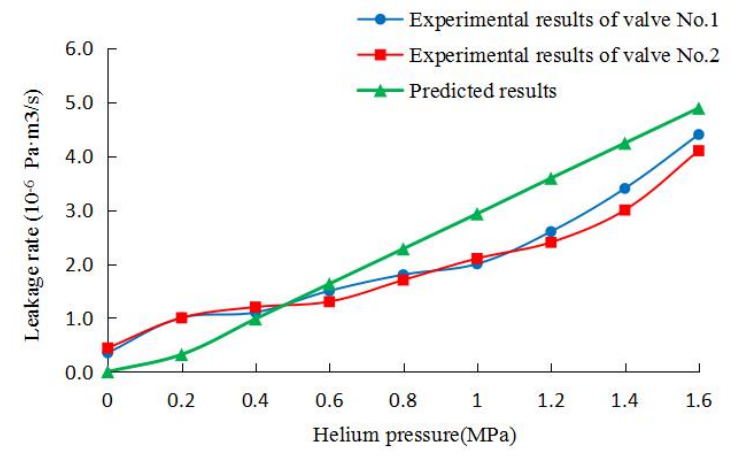

Fig. 8 Contrast Curve of Experiment and Simulation

\section{Conclusion}

The Visualization System for Valve sealing evaluation realizes the connection between VB program and ANSYS by APDL, which avoids operating ANSYS directly and reduces the difficulty of valve design analysis. Through establishing the Sealing surface model of floating ball valve, this system can simulate the contact stress of contact surface. At the same time, the floating ball valve which doesn't meet sealing requirements can be optimized by improving the seat structure and its leakage rate can be predicted by porous media model in this system.

\section{Acknowledgements}

This work is supported by the Nature Science Foundation of China (51675183) and National key research and development program (No. 2017YFF0210400).

\section{References}

[1] Lu Peiwen. 2012. Design handbook of valve in Beijing. China Machine Press, (2-3).

[2] Zhang Yifang, Wu Bin, Wang Jianxin, et al. 2015. Study on sealing characteristics of ball valve in Shenyang. Valve, Vol. 5(14-17).

[3] Huang Qibin, Yang Xiaoxiang, Deng Daolin. 2015. Spherical plain bearing structural analysis based on VB and ANSYS secondary development in Nanjing. Journal of mechanical manufacturing and automation, Vol. 1(149-151).

[4] Shi Fang. 2012. Development of ANSYS and example explanation. China Water \& Power Press in Beijing, (8).

[5] Tsai C C, Chang C Y, Tseng C H. 2004. Optimal design of metal seated ball valve mechanism in Berlin. Structural \& Multidisciplinary Optimization, Vol. 26(249-255).

[6] Huang Xiaoming, Li Jun, Xu Guoliang, et al. 2016. Study on leak mechanism and leakage rate prediction model of 
reactor containment sealing structure in Chengdu. Nuclear Power Engineering, Vol. 3(116-121).

[7] Rogula J. 2012. The influence of seat fatigue test on the leakage in ball valve in Amsterdam. Procedia Engineering, Vol. 39(91-97). 